\title{
Australian and overseas models of general practice training
}

\author{
Richard B Hays and Simon Morgan
}

$\checkmark$ eneral practice in Australia has a strong role in the health care system, setting high professional standards and an organised general practice training program. For most people seeking health care, general practice is the first point of medical contact. Most other medical services are accessed by referral from general practitioners, who therefore must be able to manage, at least initially, a wide range of health problems.

Since its establishment in 1958, the Royal Australian College of General Practitioners (RACGP) has been responsible for academic standards for this broad scope of practice. ${ }^{1}$ Professional recognition as a GP requires 3 or 4 years of training, and assessment for Fellowship. In 1974, the Australian Government funded the RACGP's Family Medicine Program, which for about 25 years, was the sole general practice training provider. ${ }^{2}$ The Australian College of Rural and Remote Medicine (ACRRM) was established in 1997 in response to concerns about rural training and workforce needs and, in 2007, was accredited to provide vocational training for general practice in Australia through its Fellowship training and assessment pathways. ${ }^{3}$

In June 2000, vocational general practice training became the responsibility of a new, independent organisation known as General Practice Education and Training. General practice training was decentralised and delivered through a network of independent regional training providers (RTPs). This model is largely government-funded, with an annual budget appropriation of $\$ 91$ million during the 2009-10 financial year, ${ }^{2}$ aiming to enhance community responsiveness and address regional workforce needs.

Hence, Australia has a structured training program, delivered through RTPs, and incorporating two sets of College curricula, training and practice standards, assessment requirements and qualifications. ${ }^{3,4}$ Training includes supervised placements in both hospitals and general practices, complemented by formal practicebased teaching and regular educational sessions.

\section{An international comparison of general practice training programs}

General practice training in Australia has evolved in response to local and overseas developments. Learning from overseas programs is complicated by variations in general practice roles across national borders. General practice is not universally a strong, firstpoint-of-contact profession. For example, the United States model sees family medicine as one of several "primary care" specialties that compete with each other for patients. Another model, commonly seen in the developing world, sees general practice as a weak, low-status occupation for doctors without specialty training and patients who cannot access specialists.

This wide international spectrum of practice, ranging in scope from broad generalist to narrower specialist, is reflected in the variety of training models. This article compares the current Australian General Practice Training program with equivalent programs in selected countries and regions - the United Kingdom and Ireland, Europe, North America, and the Asia-Pacific region - based on selected issues listed in the Box, including details of the training programs and their governance. More detailed comparative information is available elsewhere. ${ }^{5}$

\section{ABSTRACT}

- General practice training in Australia continues to evolve. It is now the responsibility of an independent organisation, is delivered by regional training providers, and comprises a structured training program.

- Overseas, general practice varies in its importance to health care systems, and training models differ considerably.

- In some cases training is mandatory, in others voluntary, but the aim is always similar - to improve the quality of care delivered to the large majority of populations that access health care through primary care.

- We review the current status of vocational general practice training in Australia, compare it with selected training programs in international contexts, and describe how the local model is well placed to address future challenges.

- Challenges include changes in population demographics, increasing comorbidity, increasing costs of technology-based health care, increasing globalisation of health, and workforce shortages.

- Although general practice training in Australia is strong, it can improve further by learning from other training programs to meet these challengers.

MJA 2011; 194: S63-S66

\section{New Zealand}

Despite having a similar health care system, New Zealand has a different approach to general practice training. Although training and certification by assessment are mandatory for recognition as a GP, there are two routes to achieving this. The formal pathway is through the Investment Relationships and Purchasing arm of Health Workforce New Zealand, which provides a limited number of funded training posts in accredited teaching practices and a comprehensive, supporting educational program. There is also an "independent" pathway, in which aspiring GPs organise and fund their own training. There are two stages of training - General Practice Education Program (GPEP) 1, a 12-month GP placement in a training practice that follows junior hospital training, and GPEP 2, a 2-year immersion in general practice, based on continuing professional development participation and workplace-based assessments. ${ }^{6}$ A primary membership examination (Primex) is taken at the completion of GPEP 1, and fellowship assessment is taken after GPEP 2.

\section{United Kingdom and Ireland}

The UK has mandatory 3-year training program for the recognised specialty of general practice. ${ }^{7}$ Individuals apply to enter after their first postgraduate year (Foundation Year 1) to individual regionalised training programs based on the Postgraduate Deaneries in the 10 Strategic Health Authorities. Assessment comprising an endpoint written and clinical objective structured clinical examination leads to Membership of the Royal College of General Practitioners, which has responsibility for standards. Rural training is available 


\section{Comparison of key features of selected general practice training systems}

\begin{tabular}{|c|c|c|c|c|c|c|c|c|c|}
\hline & \multicolumn{6}{|c|}{ Training details } & \multicolumn{3}{|c|}{ Governance } \\
\hline & Mandatory & Entry & Duration & $\begin{array}{l}\text { Defined } \\
\text { curriculum }\end{array}$ & $\begin{array}{c}\text { Formal } \\
\text { assessment }\end{array}$ & Regional & $\begin{array}{l}\text { University } \\
\text { affiliation }\end{array}$ & $\begin{array}{l}\text { Funding } \\
\text { source }\end{array}$ & $\begin{array}{c}\text { Assessment } \\
\text { independent }\end{array}$ \\
\hline Australia & Yes & PGY 2 & 3 years & Yes & Yes & Yes & Weak & Government & Yes \\
\hline New Zealand & Yes & PGY 2 & 3 years & Yes & Yes & No & Weak & Mixed & Yes \\
\hline Hong Kong & Varies & PGY2 & 6 years & Yes & Yes & No & Weak & Self & No \\
\hline Philippines & No & PGY 1 & 3 years & Yes & Yes & No & Strong & Self & No \\
\hline Malaysia & No & PGY 4 & 2 years & No & Yes & No & Weak & Self & No \\
\hline Singapore & No & PGY 2 & $1-6$ years & Yes & Yes & No & Strong & Self & No \\
\hline United Kingdom & Yes & PGY 3 & 3 years & Yes & Yes & Yes & Weak & Government & Yes \\
\hline Ireland & Yes & PGY 2 & 4 years & Yes & Yes & Yes & Weak & Mixed & No \\
\hline Northern Europe & Yes & PGY 2 & $3-5$ years & Yes & Yes & No & Weak & Government & Varies \\
\hline $\begin{array}{l}\text { Central and } \\
\text { southern Europe }\end{array}$ & Varies & Varies & Varies & Varies & Varies & Varies & Varies & Varies & Varies \\
\hline Canada & Yes & PGY 1 & 3 years & Yes & Yes & Yes & Strong & Government & Yes \\
\hline United States & Yes & PGY 1 & 3 years & Yes & Yes & Yes & Strong & Government & Yes \\
\hline
\end{tabular}

in certain regions, such as Wales and Scotland. A recent review recommended extending the duration of vocational training from 3 to 4 years, ${ }^{8}$ but as yet there is no decision.

General practice training in Ireland is a mandatory 4-year program, commencing after a 1-year internship, and is delivered through regionalised training providers. The Irish College of General Practitioners (ICGP) administers the training, including accreditation, standard setting, curriculum development and summative assessment. ${ }^{9}$ The ICGP membership examination consists of written and oral components.

\section{Europe}

Europe contains a collection of different health systems and considerable variation in general practice training models. In Northern European countries (Belgium, the Netherlands and Scandinavian countries), ${ }^{10}$ general practice is a recognised specialty and is the access point for specialist care. There are specific training programs of 3-4 years' duration, similar to the UK. Assessment processes vary considerably, from examinations to participation in continuing professional development. Other European countries have weaker general practice roles; general practice is not always recognised as a specialty, and has less well defined training programs. Some countries have voluntary general practice training programs that are similar in principle to the northern European models.

\section{North America}

Family medicine is a strong, recognised specialty in Canada, where specialist care is accessed through primary care. There is a defined curriculum approved by the College of Family Physicians of Canada, ${ }^{11}$ and an end-point examination that must be taken during the final 6 months of training. Training commences directly after medical school and is provided through province-based, university-affiliated programs, some of which offer specific rural training. The training period is only 2 years, but is more concentrated than in Australia, with 1 year in an academic family medicine practice under intense supervision.
In the US, family medicine is one of several primary care specialties (general internal medicine and paediatrics are others), and patients may self-refer directly to any specialists. There is a defined curriculum, approved by the American Board of Family Medicine, ${ }^{12}$ and training commences directly after medical school, via state- or university-based programs. Specific rural practice training programs are available in some states. Certification assessment requires computerised knowledge testing, covering a wide range of knowledge and problem-solving abilities.

\section{"Commonwealth" Asia}

Perhaps because of their common colonial British heritage, Malaysia, Hong Kong and Singapore have similar general practice vocational training arrangements, commencing after a basic medical education degree. General practice is moderately strong, although not a requirement for patient access to specialists. Voluntary training is available and leads to recognised qualifications. $^{13}$

In Malaysia, the "high-quality" route to practice is a self-directed training program following 3 years of mandatory community service as a junior doctor. Trainees may then either complete a 2 year, mentored distance-education course that leads to a Diploma in Family Medicine, or sit the conjoint RACGP-Malaysian Fellowship exam. ${ }^{14}$ Some doctors complete both requirements.

In Hong Kong, the Hong Kong College of Family Physicians (HKCFP) has a 6-year (4 years basic, 2 years higher) specialty training program that is assessed by both an exit and a conjoint HKCFP-RACGP Fellowship examination.

Singapore has a joint government-university-private practice approach and a three-level training pathway. The first level is a 1-year, flexibly delivered training program leading to a Diploma in Family Medicine. The second level is a 3-year, higher-level training program that results in a Masters degree. The third level is Fellowship of the College of Family Physicians, which offers a further 2 years of training for members who wish to be regarded as leaders of the profession. 


\section{"Non-Commonwealth" Asia-Pacific region}

The rest of Asia and the western Pacific have variable arrangements. General practice is often weak, with little specific training or recognition. Some countries, particularly the Philippines and Japan, have US-style primary care and training programs. ${ }^{15}$ The Pacific island states, including Fiji and Papua New Guinea, have weak general practice roles, with no formal recognition as a specialty and no specific training or certification processes.

\section{Reciprocity of training}

The RACGP has bilateral agreements with equivalent professional bodies in several countries that may accelerate recognition of GPs who move between countries. Such arrangements are usually restricted to those who can demonstrate that they have completed a defined training program and passed a specialty "certification" examination. This allows direct passage, without further training, to either the local certification examination or a portfolio-based assessment of suitability for practice. These arrangements exist between Australia and New Zealand, Canada, the US, Ireland, the UK and Singapore. Those who have passed the conjoint RACGP examinations in Malaysia and Hong Kong are also eligible for Australian recognition. However, the arrangements vary somewhat between countries, are subject to change, and require appropriate immigration and basic licensing procedures, so precise arrangements should be checked.

\section{How do we compare and what can we learn?}

Internationally, general practice and general practice training face several challenges, including: rapidly ageing populations; increasing burdens of chronic disease and comorbidities; increasing community-based health care delivery; balancing a burgeoning evidence base with holistic, patient-centred care; and workforce shortages, particularly in rural areas. How is the Australian vocational training system placed to address these challenges compared with its international counterparts? What can Australia learn from training programs elsewhere?

Australian vocational general practice training has several strengths. The existing structures and processes are rigorous by international standards. Formal training is mandatory for vocational recognition, and there are robust training standards, and assessment and accreditation processes. Both the RACGP and the ACRRM curricula reflect community needs, including specific coverage of Aboriginal health, rural health, multicultural health, population health, procedural skills, workforce development and GPs as teachers. The separation of delivery of training from curriculum and assessment standards is sound. The RACGP examination has proven validity and reliability, ${ }^{16}$ and the ACRRM assessment pathway is demonstrating potential to address extended rural practice workforce development. ${ }^{17}$

Despite these strengths, lessons can be learned from elsewhere in facing current challenges. The first challenge relates to the model of training and delivery of "core" curricular content. The current model, preferred by mainstream general practice, is clinical apprenticeship. This potentially exposes trainees to a wide range, and changing patterns, of patient demographics and clinical presentations - the "curriculum walks in the door". However, this variability may lengthen the training time necessary to cover core learning. Could training be made shorter and more efficient? In North America, patient contact and training arrangements are more standardised in teaching practice managed by university departments. In Australia, however, not all relationships between RTPs and universities are strong.

The second challenge is how to respond to pressure to expand the medical workforce through increasing registrar numbers and hastening training completion. Can training capacity be increased without reducing the current flexibility? The popularity of general practice training may fall if there are reductions in recognition of prior learning, part-time training, additional "special skills" training and generous leave entitlements, as these are important issues for registrars as gender mix and work patterns evolve. The New Zealand independent pathway is seen as one way to increase capacity without additional cost, but are the standards the same as in the formal pathway?

This raises the third challenge - the complex, difficult to compare, issue of funding. Australian Government funding for general practice training is relatively generous, higher than in New Zealand, where there is a partial "user-pays" system, but lower than in the UK, where registrars' salaries in general practice terms are paid in full. There are no data comparing the cost efficiency and quality of international models of GP training, so any decision on this issue may be a compromise between politics and professional norms.

The fourth challenge, which is shared with the rest of the developed world, is the shift in focus of health care delivery and medical education from hospitals to the community. As a result, an increasing number of undergraduate and postgraduate health care learners are now concentrated in community settings. ${ }^{18,19}$ Following the recent expansion of undergraduate medical education, the number of Australian medical graduates will double by about 2014. ${ }^{20}$ While this will increase competition for training places in general practice, the strong emphasis on providing registrars with teaching skills in vertically integrated training facilities may enhance general practice teaching capacity, ${ }^{20,21}$ although this may take some time.

The fifth challenge, addressing the increasing cost of technology-based health care, is difficult to achieve in general practice training. While the government aims to increase the role of primary medical care, where expensive investigations tend to be less necessary and less available, general practice training generally lags behind the evolution of the role of general practice. The most notable exception to this is in the UK, where general practice training is closely linked to health system structures. Australia should consider improving the training of GPs for the broader health care management roles that the government wants them to adopt.

The sixth challenge is how to ensure that general practice training produces graduates with the skills to critically appraise the expanding information and evidence base for medical practice. The Australian focus on research literacy may be less than elsewhere: for example, all GP registrars in the UK must complete a formal clinical audit. ${ }^{7}$ Although the curricula of both Australian Colleges specifically include research, critical appraisal and evidence-based medicine, teaching and assessment in these areas vary considerably, with only some individual RTPs requiring participation in a research project. ${ }^{22}$

The final challenge is the impact of globalisation on health care. Although reciprocity exists for Australian and selected other jurisdictional qualifications, these arrangements are based on similar practice styles and training systems. Australian curricula 
are relatively weak on preparing GPs for work in the broader international environment, and particularly in developing countries. Although this is not regarded as a priority for Australian general practice training, the successful internationalisation of undergraduate medical education in Australia may be an example to follow, potentially increasing the relevance and status of Australian GP training to an increased range of countries than currently in reciprocal arrangements.

\section{Conclusion}

General practice training in Australia has evolved from a voluntary process for a minority of GPs into a high-quality system with a defined curriculum and certification assessment for a recognised specialty. This reflects the central role of primary care in the health system. The management and delivery of training occurs through RTPs, and is separated from the Colleges, which provide the standards of practice and training. There are strong similarities between training in Australia and training in the many other countries, and reciprocal recognition is allowed with some of these countries. Despite these strengths, there is room to improve further through learning from how other countries' training programs approach efficiency and funding of training, the globalisation of health care and the relationship between training and evolving health system roles.

\section{Competing interests}

None identified.

\section{Author details}

Richard B Hays, PhD, MD, FRACGP, Dean ${ }^{1}$

Simon Morgan, MB BS, FRACGP, Medical Educator ${ }^{2}$

1 Faculty of Health Sciences and Medicine, Bond University, Gold

Coast, QLD.

2 General Practice Training Valley to Coast, Mayfield, NSW.

Correspondence: rhays@bond.edu.au

\section{References}

1 Royal Australian College of General Practitioners. The history of the RACGP. http://www.racgp.org.au/history (accessed Aug 2010).

2 General Practice Education and Training. Agency resources and planned performance. 2009-2010. http://www.health.gov.au/internet/budget/ publishing.nsf/Content/2009-2010_Health_PBS_sup4/\$File/General\%20Practice\%20Education\%20and\%20Training\%20Ltd.pdf (accessed Aug 2010).
3 Royal Australian College of General Practitioners. RACGP general practice vocational training standards. http://www.racgp.org.au/vocationaltraining/standards (accessed Aug 2010).

4 Royal Australian College of General Practitioners. Regional training providers. http://www.racgp.org.au/gpet (accessed Aug 2010).

5 Hays RB. Vocational and postgraduate training. In: Oxford textbook of primary medical care. Oxford: Oxford University Press, 2004: 543-546.

6 Royal New Zealand College of General Practitioners. General practice education programme. http://www.rnzcgp.org.nz/general-practice-education-programme (accessed Jun 2010).

7 Royal College of General Practitioners. GP training. http:// www.rcgp.org.uk/gp_training.aspx (accessed Aug 2010).

$8 \mathrm{MMC}$ Inquiry Panel (Tooke J, Chair). Aspiring to excellence. Findings and recommendations of the Independent Inquiry into Modernising Medical Careers. London: Aldridge Press, 2007. http://www.mmcinquiry.org.uk/ MMC_InquiryReportREVD3.pdf (accessed Aug 2010).

9 Irish College of General Practitioners. Becoming a GP. http:// www.icgp.ie/go/become_a_gp (accessed Aug 2010).

10 Sammut MR, Lindh M, Rindlisbacher B, et al. Funding of vocational training programmes for general practice/family medicine in Europe. Eur J Gen Pract 2008; 14: 83-88.

11 College of Family Physicians of Canada. Education. http://www.cfpc.ca/ Education (accessed Aug 2010).

12 American Board of Family Medicine. Residency training. https:// www.theabfm.org/residency/index.aspx (accessed Aug 2010).

13 Goh GL, Fabb WE. Family medicine development in the Asia-Pacific Region. Sing Fam Physician 2001; 27: 31-41.

14 Khoo EM, Kidd MR. Primary health care and general practice - a comparison between Australia and Malaysia. Asia Pac J Public Health 2002; 14: 59-63.

15 Leopando ZE, Olazo RA. Training specialists in family medicine in the Philippines. Aust Pac Fam Med 2003; 2: 38-41.

16 Hays RB, van der Vleuten CPM, Fabb WE, Spike N. Longitudinal reliability of the FRACGP exam. Med Educ 1995; 29: 317-321.

17 Smith JD, Prideaux D, Wolfe CL, et al. Developing the accredited postgraduate assessment program for Fellowship of the Australian College of Rural and Remote Medicine. Rural Remote Health 2007; 7: 805 .

18 Hays RB. Evolving community-based medical education: integrating undergraduate and postgraduate education. Educ Prim Care 2008; 19 : 235-240.

19 Thistlethwaite J, Kidd MR, Hudson JN. General practice: a leading provider of medical student education in the 21st century. Med J Aust 2007; 187: 124-128.

20 Joyce CM, Stoelwinder JU, McNeil JJ, Piterman L. Riding the wave: current and emerging trends in graduates from Australian university medical schools. Med J Aust 2007; 186: 309-312.

21 Royal Australian College of General Practitioners. GPs as teachers and mentors. RACGP curriculum. http://www.racgp.org.au/curriculum\#downloadcurriculum (accessed Aug 2010).

22 Anderson K, Thomson J. Vertical integration — reducing the load on GP teachers. Aust Fam Physician 2009; 38: 907-910

(Received 18 Aug 2010, accepted 24 Nov 2010) 